\title{
APRESENTAÇÃO
}

A Fundação Nacional de Saúde, através do presente número da prestigiada Revista da Sociedade Brasileira de Medicina Tropical, vem divulgar os resultados das pesquisas selecionadas e apoiadas pelo - Projeto de Controle de Endemias no Nordeste (PCDEN) - viabilizado por acordo de financiamento desta Fundação com o Banco Mundial.

O processo de implementação do componente de pesquisa do PCDEN, iniciado em 1994, apresentou alguns aspectos inovadores na forma de apoio da Fundacão Nacional de Saúde em relação aos projetos de pesquisa operacional. Embora as instituiçñes acadêmicas tivessem, no passado, realizado projetos de pesquisa em campo na área de atuação dos serviços de saúde, nem sempre esses dois universos de compreensão e intervenção sobre a realidade sanitária estiveram agindo de forma integrada. A proposta de manter a tirme aderência deste componente as demais ações voltadas ao controle das endemias - ao invés de administrá-lo à parte como um subsetor acadêmico - permite, agora, que possa ser avaliado como elemento integrante do esforço conjunto no controle da esquistossomose, doença de Chagas e leishmaniose, objeto da atuação institucional.

A inexistência, na Fundação Nacional de Saúde, dos mecanismos administrativos próprios para gerenciar, na sua complexidade, a área de pesquisa, ocasionou, sem dúvida, dificuldades para os pesquisadores e para o andamento dos projetos. Entretanto, foi acertada a decisão de manter o processo de definição temática no âmbito da Fundação, procurando estimular em técnicos atuantes a reflexão sobre prioridades de investigação, e permitir aos pesquisadores a visualização da demanda por pesquisas, gerada na prática dos serviços. Temos agora todo um percurso a percorrer na busca de aproximação desses pólos complementares, fechando paulatinamente us espaços onde atuam de forma isolada e eqüidistante.

A Fundação Nacional de Saúde agradece a contribuição inestimável da participação de representantes indicados pelas associações acadêmicas (SBMT e ABRASCO) e pelos Conselhos de Saúde (CONASS e CONASEMS) na Comissão Técnica do Componente de Pesquisa Operacional do PCDEN, e, igualmente, a atuação destacada da Prof ${ }^{a}$. Vanize de Oliveira Macêdo na referida comissão. Finalmente, presta homenagem póstuma ao emérito Prof. Amaury Coutinho que, tendo participado do Projeto como pesquisador, infelizmente não pode estar conosco neste número.

\section{Edmundo Juarez}

Presidente da Fundação Nacional de Saúde 